\title{
Effect of intellectual enrichment on AD biomarker trajectories
}

\author{
Longitudinal imaging study \\ OPEN
}

Prashanthi Vemuri, PhD

Timothy G. Lesnick, MS

Scott A. Przybelski, BS

David S. Knopman, MD

Mary Machulda, PhD, LP

Val J. Lowe, MD

Michelle M. Mielke, PhD

Rosebud O. Roberts,

$\mathrm{MBChB}$

Jeffrey L. Gunter, PhD

Matthew L. Senjem, MS

Yonas E. Geda, MD

Walter A. Rocca, MD, $\mathrm{MPH}$

Ronald C. Petersen, PhD, MD

Clifford R. Jack, Jr., MD

Correspondence to

Dr. Vemuri:

vemuri.prashanthi@mayo.edu

\section{Supplemental data} at Neurology.org

\section{ABSTRACT}

Objective: To investigate the effect of age, sex, APOE4 genotype, and lifestyle enrichment (education/occupation, midlife cognitive activity, and midlife physical activity) on Alzheimer disease (AD) biomarker trajectories using longitudinal imaging data (brain $\beta$-amyloid load via Pittsburgh compound B PET and neurodegeneration via ${ }^{18}$ fluorodeoxyglucose (FDG) PET and structural MRI) in an elderly population without dementia.

Methods: In the population-based longitudinal Mayo Clinic Study of Aging, we studied 393 participants without dementia (340 clinically normal, 53 mild cognitive impairment; 70 years and older) who had cognitive and physical activity measures and at least 2 visits with imaging biomarkers. We dichotomized participants into high ( $\geq 14$ years) and low ( $<14$ years) education levels using the median. For the entire cohort and the 2 education strata, we built linear mixed models to investigate the effect of the predictors on each of the biomarker outcomes.

Results: Age was associated with amyloid and neurodegeneration trajectories; APOE4 status appears to influence only the amyloid and FDG trajectories but not hippocampal volume trajectory. In the high-education stratum, high midlife cognitive activity was associated with lower amyloid deposition in APOE4 carriers. APOE4 status was associated with lower FDG uptake in the entire cohort and in participants with lower education but not the high-education cohort.

Conclusions: There were minimal effects of lifestyle enrichment on AD biomarker trajectories (specifically rates). Lifetime intellectual enrichment (high education, high midlife cognitive activity) is associated with lower amyloid in APOE4 carriers. High education is protective from the APOE4 effect on FDG metabolism. Differing education levels may explain the conflicting results seen in the literature. Neurology ${ }^{\circledR} 2016 ; 86: 1128-1135$

\section{GLOSSARY}

AD = Alzheimer disease; FDG = ${ }^{18}$ fluorodeoxyglucose; $\mathbf{M C I}=$ mild cognitive impairment; $\mathbf{M C S A}=$ Mayo Clinic Study of Aging; MET = metabolic equivalent; MPRAGE = magnetization-prepared rapid gradient echo; PCA = principal components analysis; $\mathbf{P i B}=$ Pittsburgh compound $\mathrm{B} ; \mathbf{R O I}=$ region of interest $; \mathbf{T I V}=$ total intracranial volume.

Better intellectual and physical activity lifestyles have increasingly been viewed as protective strategies against cognitive decline in the elderly. ${ }^{1,2}$ While lifestyle enrichment is associated with better cognitive performance, there is no clear consensus on the influence of lifestyle enrichment on ongoing Alzheimer disease (AD) pathophysiology through longitudinal biomarker studies. The primary goal of this study was to examine the effect of lifestyle enrichment variables on $A D$ biomarker values taking into account demographics and APOE4 status, both cross-sectionally and longitudinally, in an elderly population-based sample without dementia.

Several recent studies have examined the effect of lifestyle enrichment on biomarkers crosssectionally. The use of different cohorts, sample sizes, and constructs of enrichment has contributed to conflicting results in the literature. ${ }^{3-10}$ An important difference we observed across the

\footnotetext{
From the Departments of Radiology (P.V., V.J.L., J.L.G., M.L.S., C.R.J.), Health Sciences Research (T.G.L., S.A.P., M.M.M., R.O.R., W.A.R.), Neurology (D.S.K., M.M.M., R.O.R., W.A.R., R.C.P.), and Psychology (M.M., Y.E.G.), Mayo Clinic, Rochester, MN; and Departments of Psychiatry (Y.E.G.) and Neurology (Y.E.G.), Mayo Clinic, Scottsdale, AZ.

Go to Neurology.org for full disclosures. Funding information and disclosures deemed relevant by the authors, if any, are provided at the end of the article. The Article Processing Charge was paid by the authors.

This is an open access article distributed under the terms of the Creative Commons Attribution-NonCommercial-NoDerivatives License 4.0 (CC BY-NC-ND), which permits downloading and sharing the work provided it is properly cited. The work cannot be changed in any way or used commercially.
} 
studies was the level of education. Typically, participants recruited through advertisements and after thorough screening have higher levels of education, which is often the main underlying variable of interest. Since educational attainment occurs during sensitive periods of brain development, it plays a key role throughout the lifespan, and may have a significant impact on $\mathrm{AD}$ biomarker trajectories. We hypothesized that the conflicting results (regarding the effect of lifestyle enrichment on $\mathrm{AD}$ biomarkers) seen in the literature (see Discussion) may be partly explained by different education levels of the cohort. We further hypothesized that the effects of demographics and lifestyle variables on the $\mathrm{AD}$ biomarker trajectories may differ based on education levels. Therefore, in this article we specifically examine the effects of demographics and lifestyle enrichment variables on $\mathrm{AD}$ biomarker trajectories in participants with high and low education.

In this article, we use longitudinal imaging data from the Mayo Clinic Study of Aging (MCSA), which is a population-based sample of elderly without dementia. We used the following imaging biomarkers as surrogates of the major $\mathrm{AD}$ processes: Pittsburgh compound $\mathrm{B}$ (PiB) PET imaging as a biomarker of cerebral amyloidosis, ${ }^{18}$ fluorodeoxyglucose (FDG) PET imaging as an indicator of AD-related changes in brain metabolism, and hippocampal volume measured by structural MRI as an indicator of neurodegeneration due to $\mathrm{AD}$.

METHODS Selection of participants. Study participants were participants in the MCSA, an epidemiologic study of the prevalence, incidence, and risk factors for mild cognitive impairment (MCI) and dementia among Olmsted County residents ages 70-89 years. The participants consisted of the original cohort sampled from the October 1, 2004, enumeration of the county population, and replenishment cohorts sampled from the 2008, 2009, 2010, and 2011 enumeration. The MCSA uses the Rochester Epidemiology Project medical records linkage system to enumerate the county population ${ }^{11}$ and samples are randomly selected for participation. We included all 393 participants without dementia (340 clinically normal, $53 \mathrm{MCI}$ ) with $A P O E$ genotype, intellectual lifestyle, physical activity lifestyle, and at least 2 complete sets of $\mathrm{AD}$ biomarker measurements (PiB, FDG, MRI). More extensive details of the MCSA design have been published elsewhere. ${ }^{12,13}$

Standard protocol approvals, registrations, and patient consents. These studies were approved by the Mayo Clinic and Olmsted Medical Center institutional review board. Informed consent was obtained from all participants or their surrogates.
AD biomarkers. MRI acquisition and processing. All participants were scanned on 3T MRI scanners and a 3D volumetric T1- magnetization-prepared rapid gradient echo (MPRAGE) was acquired and preprocessed as described previously. ${ }^{14}$ Freesurfer software (version 5.3) with a longitudinal processing pipeline was used to obtain total hippocampal volumes on serial MRI scans. ${ }^{15}$ Total intracranial volume was estimated using MPRAGE scans using an in-house method. ${ }^{16}$

PET acquisition and processing. Images were acquired with a PET/CT operating in 3D mode (septa removed). More extensive details of PET acquisition were described previously. ${ }^{17}$ All PET quantitative image analysis, including quality control, was performed at the Mayo Clinic using the same fully automated image processing pipeline as described previously. ${ }^{16,18}$ Statistics on image voxel values were extracted from automatically labeled cortical regions of interest using an in-house modification of the automated anatomic labeling atlas. ${ }^{19}$

Global PiB-PET ratio measure. A global cortical PiB-PET measure was computed for each individual scan by calculating the median uptake over voxels in the prefrontal, orbitofrontal, parietal, temporal, anterior cingulate, and posterior cingulate/precuneus regions of interest (ROIs) for each participant and dividing this by the median uptake over voxels in the cerebellar gray matter ROI of the atlas.

Global FDG-PET ratio measure. A global FDG-PET retention summary was computed for each individual scan by averaging the left and right angular gyri, bilateral posterior cingulate, and left middle/inferior temporal gyrus values for each participant as described previously $y^{20}$ normalized by the pons uptake.

Lifestyle enrichment variables. We used the following lifestyle enrichment variables from the MCSA. These were recorded for the majority of participants at the baseline or enrollment visit. For patients with multiple evaluations, the variables collected closest in time to the MRI/PET scan date were used in the analyses. Details about the individual questions that were part of the cognitive and physical activity questionnaires are provided in our previous work. ${ }^{21}$

Intellectual lifestyle. The primary intellectual activity variables of interest included the following. (1) Education and primary occupation throughout life. Education and occupation are highly correlated variables; therefore we used principal components analysis (PCA) to form a consolidated variable (education/occupation score) similar to our previous work ${ }^{21}$ to reduce the numbers of predictor variables. (2) Midlife weekly cognitive activity (ages 50-65 years) was summarized based on self-report questionnaire ${ }^{21}$ (supplemental material on the Neurology ${ }^{\circledR}$ Web site at Neurology.org).

Physical activity lifestyle. We used a midlife physical activity score (ages 50-65 years) based on self-report questionnaire ${ }^{21}$ (supplemental material). In this article, we created a physical activity composite score by weighting each individual component with metabolic equivalent (MET) scores. ${ }^{22,23}$ These MET scores assign intensities to physical activity questionnaire items, and allow differentiation of light from heavy activities and exercises. We then again used PCA to form a consolidated variable.

Statistical analysis. We examined baseline age, sex, APOE4 genotype, and lifestyle enrichment variables (education/occupation, midlife cognitive activity, and midlife physical activity) as potential predictors of longitudinal biomarker values using linear mixed models. In the entire cohort, we initially fit 3 separate models for each of the $\mathrm{AD}$ biomarkers: global PiB ratio, global FDG ratio, and total hippocampal volume (data in figure e-1). 
Table 1 Patient characteristics at baseline in the overall sample and in the strata by education

\begin{tabular}{|c|c|c|c|c|}
\hline Characteristics & $\begin{array}{l}\text { All participants } \\
(\mathrm{n}=393)\end{array}$ & $\begin{array}{l}\text { Low education } \\
(\mathrm{n}=188)\end{array}$ & $\begin{array}{l}\text { High education } \\
(\mathrm{n}=205)\end{array}$ & $p$ Value $^{a}$ \\
\hline \multicolumn{5}{|l|}{ Demographics } \\
\hline Female & 149 (38) & $77(41)$ & 72 (35) & 0.23 \\
\hline APOE4 carriers & $109(28)$ & $50(27)$ & $59(29)$ & 0.63 \\
\hline Age at MRI, y & $78.6(5.0)$ & $78.5(5.4)$ & $78.8(4.6)$ & 0.58 \\
\hline $\mathrm{MCl}$ & 53 (13.5) & 28 (14.9) & 25 (12.2) & 0.43 \\
\hline Follow-up time, y & 2.5 (1.2) & $2.4(1.1)$ & 2.7 (1.2) & 0.04 \\
\hline \multicolumn{5}{|l|}{$\begin{array}{l}\text { Lifestyle enrichment } \\
\text { variables }\end{array}$} \\
\hline Education, y & $14.3(3.0)$ & $11.8(1.4)$ & $16.6(2.0)$ & $<0.001$ \\
\hline Job level, score & 4.2 (1.5) & $3.3(1.0)$ & $5.1(1.4)$ & $<0.001$ \\
\hline $\begin{array}{l}\text { Midlife cognitive } \\
\text { activity, score }\end{array}$ & 20.7 (8.7) & $18.9(8.4)$ & $22.5(8.7)$ & $<0.001$ \\
\hline $\begin{array}{l}\text { Midlife physical } \\
\text { activity, score }\end{array}$ & $41.9(25.4)$ & $45.2(26.9)$ & $38.9(23.7)$ & 0.01 \\
\hline $\begin{array}{l}\text { Midlife exercise } \\
\text { activity, score }\end{array}$ & $39.6(29.7)$ & 38.7 (31.8) & $40.4(27.7)$ & 0.57 \\
\hline \multicolumn{5}{|l|}{ AD biomarkers } \\
\hline $\begin{array}{l}\text { Hippocampal } \\
\text { volume, } \mathrm{mL}\end{array}$ & $6.74(0.92)$ & $6.71(0.94)$ & $6.77(0.90)$ & 0.52 \\
\hline Amyloid load, SUVR & $1.55(0.36)$ & $1.53(0.34)$ & $1.56(0.38)$ & $0.39^{b}$ \\
\hline FDG uptake, SUVR & $1.40(0.15)$ & $1.38(0.15)$ & $1.41(0.15)$ & 0.10 \\
\hline
\end{tabular}

Abbreviations: $A D=$ Alzheimer disease; $F D G=18$ fluorodeoxyglucose; $\mathrm{MCl}=$ mild cognitive impairment; SUVR = standardized uptakevalueratio.

Values are $n(\%)$ or mean (SD).

${ }^{a}$ The $p$ values are from a $t$ test for the continuous variables or $\chi^{2}$ test for differences in proportions between the low-education and high-education cohorts.

${ }^{b}$ This $p$ value comes from a $t$ test in which the log of Pittsburgh compound $B$ was calculated.

We then conducted stratified analyses using the median education level of 14 as a cutpoint to investigate differences between high- and low-education groups. In the models for amyloid, global PiB was log transformed and also reversed in sign so that larger values would correspond to lower amyloid burdens. In the models for hippocampal volume, we included total intracranial volume (TIV) as a covariate. We included all 2-way interactions with time in the group of potential predictors. In these linear mixed models, a significant interaction of a predictor with time would indicate that the rate of change of the outcome over time differs according to the value of the predictor variable (nonparallel over time). In the absence of that interaction, a significant predictor would indicate that the rate of change in the outcome over time would be consistent (parallel over time) but shifted according to the value of the predictor variable. We also included interactions with sex and APOE4.

Because of the large number of potential predictor variables, we used a Lasso-type penalization procedure for linear mixed models to select a parsimonious model for each biomarker outcome ${ }^{24}$ while respecting the need to retain nested terms. These methods are implemented in the R package lmmlasso. This method shrinks regression coefficient estimates to zero for some predictor variables, thereby dropping them from the model. It has good statistical accuracy for prediction and is computationally manageable. Per the recommendations of the developer, we selected the regularization parameters controlling the penalization (and hence the number of regression coefficients set to zero) by minimizing the Bayesian information criterion. Final parameter estimates, standard errors, and $p$ values were obtained for the parsimonious models using standard linear mixed models fit with random participant-specific intercepts and slopes. We tested for the statistical significance of these random terms using likelihood ratio tests, and found that all were necessary (all $p$ values $<0.0001$ ). Since we did not find significant associations of lifestyle enrichment variables or sex with biomarker values, we tested to see if we had adequate power to detect important associations. Detailed power analyses are included in the supplemental material.

RESULTS The demographics, APOE4 status, lifestyle enrichment variables, and baseline $\mathrm{AD}$ biomarker values of all the participants and those in the 2 education-stratified groups are shown in table 1. Age, sex, and APOE4 status were not significantly different between the low- and high-education cohorts. The greater mean follow-up time for higheducation participants $(p=0.04)$ was primarily driven by a few participants with large follow-up times. Since the times were positively skewed, we also ran a Wilcoxon rank sum test, which had $p=$ 0.09 . Any influence of follow-up time should thus be minimal. The number of visits per participant did not differ between the groups $(p=0.31)$. Persons with higher education had higher job level scores as well as higher midlife cognitive activity levels, as expected $(p<0.001)$. The baseline AD biomarker values were not different between higheducation and low-education groups ( $p \geq 0.1$ ).

The results of the linear mixed effect models for the entire cohort are presented in table 2 . The results of the 3 linear mixed effects models are presented in table $3 \mathrm{~A}$ for those with high education ( $\geq 14$ years) and in table $3 \mathrm{~B}$ for those with low education $(<14$ years). Figure 1 illustrates the predicted biomarker trajectories in the entire cohort as a function of age. The top panel in figure 2 illustrates the predicted biomarker trajectories in the high-education cohort and bottom panel in figure 2 illustrates the predicted biomarker trajectories in the low-education cohort as a function of age.

Models for prediction of amyloid deposition. In the amyloid models for the entire cohort as well as the education-stratified cohorts, older age and APOE4 status was associated with worse amyloid levels $(p<$ 0.05). In the entire cohort amyloid model, APOE4 status was also associated with faster rate of increase in amyloid deposition $(p<0.001)$. In the model of amyloid deposition for high education levels, high midlife cognitive activity was associated with lower amyloid deposition in APOE4 carriers (coefficient $=$ $0.0630, p<0.05$ ). Midlife physical activity was not associated with the amyloid trajectories.

Models for prediction of FDG uptake. In the FDG uptake models for the entire cohort and both the 
Table 2 Models for predictors of each of the Alzheimer disease biomarker trajectories in the entire cohort $(n=393)$

\begin{tabular}{|c|c|c|c|}
\hline Variable & Coefficient & SE & p Value \\
\hline \multicolumn{4}{|l|}{ Model 1: Amyloid deposition ${ }^{a}$} \\
\hline Intercept & 0.2895 & 0.1498 & 0.0539 \\
\hline Time from baseline, $y$ & -0.01687 & 0.0012 & $<0.0001$ \\
\hline Baseline age, y & -0.0084 & 0.0019 & $<0.0001$ \\
\hline APOE4 & -0.1398 & 0.0216 & $<0.0001$ \\
\hline APOE4 $\times$ time from baseline, $y$ & -0.0100 & 0.0024 & $<0.0001$ \\
\hline \multicolumn{4}{|l|}{ Model 2: FDG uptake } \\
\hline Intercept & 1.9970 & 0.1162 & $<0.0001$ \\
\hline Time from baseline, $y$ & -0.0111 & 0.0017 & $<0.0001$ \\
\hline Baseline age, y & -0.0075 & 0.0015 & $<0.0001$ \\
\hline APOE4 & -0.0413 & 0.0163 & 0.0116 \\
\hline \multicolumn{4}{|l|}{ Model 3: Hippocampal volume } \\
\hline Intercept & 9.0896 & 0.7112 & $<0.0001$ \\
\hline TIV & 0.0019 & 0.0002 & $<0.0001$ \\
\hline Time from baseline, $y$ & 0.1150 & 0.0711 & 0.1065 \\
\hline Baseline age, y & -0.0660 & 0.0083 & $<0.0001$ \\
\hline Baseline age, $y \times$ time from baseline, $y$ & -0.0025 & 0.0009 & 0.0051 \\
\hline
\end{tabular}

Abbreviations: FDG = 18fluorodeoxyglucose; TIV = total intracranial volume.

${ }^{a}$ This model uses $-\ln ($ Pittsburgh compound B) as the outcome.

education strata, older age was associated with low FDG uptake $(p<0.05)$. In the FDG models for the entire cohort and the low-education cohort, APOE4 status was associated with worse FDG uptake $(p<0.05)$. None of the enrichment variables was associated with FDG uptake.

Models for prediction of hippocampal volume. In all of the models with hippocampal volume as an outcome, increasing age was associated with lower hippocampal volume. As expected, larger TIV was a predictor of larger hippocampal volume $(p<0.001)$. In the model of hippocampal volume with the entire cohort, age was a predictor of faster annual rate of hippocampal volume decline. None of the enrichment variables was associated with hippocampal volume.

DISCUSSION The major conclusions of the study are as follows. (1) We observed minimal effects of lifestyle enrichment variables (education/occupation, midlife cognitive activity, and midlife physical activity) on the $\mathrm{AD}$ biomarker trajectories (specifically the rate of worsening). (2) Highly educated APOE4 carriers with high midlife cognitive activity have lower amyloid burden than highly educated APOE4 carriers with low midlife cognitive activity. (3) Age was associated with both amyloid and neurodegeneration biomarker trajectories; APOE4 status appears to influence only the amyloid and FDG trajectories but not hippocampal volume trajectory. (4) APOE4 status was not associated with lower FDG uptake in the high-education cohort but was associated with lower FDG uptake in the entire cohort and lower education cohort.

For all the models predicting amyloid deposition, older age and APOE4 status were significantly associated with higher levels of amyloid deposition. Only the entire cohort model showed an association between APOE4 status and faster rate of amyloid deposition, which can be attributed to the larger sample required for detecting small effects (observed coefficient was 0.01). These findings are consistent with the literature that has shown a significant impact of age and APOE4 on amyloid deposition. ${ }^{16,25,26}$ In our earlier cross-sectional studies, we did not find an association between amyloid and lifestyle enrichment ${ }^{21}$ similar to the results we found when we considered the entire cohort (figure 1). Some recent studies support the findings of no association between amyloid deposition and cognitive activity. ${ }^{3-5}$ However, after dichotomizing participants into high education and low education, we observed associations of high midlife cognitive activity with lower amyloid deposition in APOE4 participants with high education. The effects of lifestyle on amyloid deposition in our study are similar to those found in studies with participants with high education (median $\geq 16$ years). ${ }^{6-10}$ There is also literature supporting our findings of reduced $\mathrm{AD}$ risk due to lifestyle modification, specifically in APOE4 carriers. ${ }^{10,27-30}$ The analyses conducted in this article make an important point that high-education cohorts are likely to find an association of high lifestyle enrichment with low amyloid deposition. The conclusions were the same when education and occupation were considered as separate variables.

There are several possible explanations for the observation that highly educated APOE4 carriers with high midlife cognitive activity have lower amyloid burden than highly educated APOE4 carriers with low midlife cognitive activity. (1) Higher levels of education and higher levels of midlife cognitive activities somehow forestall amyloid deposition, which is evident in APOE 4 carriers because APOE4 carriers are accumulating amyloid at an earlier age and at a faster rate than $A P O E 4$ noncarriers. ${ }^{16,31}$ With greater power, we might see the same protective association in $A P O E 4$ noncarriers. The problem is that there is not a good biological explanation of how these features could forestall amyloid deposition. (2) A reverse causality explanation: APOE4 carriers are more likely to experience an earlier elevation of brain amyloid. ${ }^{16}$ Among all educated APOE4 carriers, those with the highest amyloid levels in middle age are most likely to experience subtle cognitive symptoms at that time and consequently avoid strenuous intellectual activity, thus placing them in the low cognitive activity group. 
Table 3 Models for predictors of each of the Alzheimer disease biomarker trajectories: Participants with high education $(n=205 ; \geq 14$ years) and participants with low education $(n=188 ;<14$ years)

\begin{tabular}{|c|c|c|c|}
\hline Variable & Coefficient & SE & p Value \\
\hline \multicolumn{4}{|l|}{ A. High education models ( $\geq 14 \mathrm{y}$ ) } \\
\hline \multicolumn{4}{|l|}{ Model 1: Amyloid deposition ${ }^{a}$} \\
\hline Intercept & 0.3919 & 0.2381 & 0.1010 \\
\hline Time from baseline, $y$ & -0.0192 & 0.0015 & $<0.0001$ \\
\hline Baseline age, $y$ & -0.0099 & 0.0030 & 0.0012 \\
\hline APOE4 & -0.1208 & 0.0301 & 0.0001 \\
\hline Cognitive midlife & -0.0059 & 0.0163 & 0.7190 \\
\hline APOE $4 \times$ cognitive midlife & 0.0630 & 0.0297 & 0.0351 \\
\hline \multicolumn{4}{|l|}{ Model 2: FDG uptake } \\
\hline Intercept & 2.1353 & 0.1734 & $<0.0001$ \\
\hline Time from baseline, $y$ & -0.0122 & 0.0026 & $<0.0001$ \\
\hline Baseline age, $y$ & -0.0092 & 0.0022 & $<0.0001$ \\
\hline \multicolumn{4}{|l|}{ Model 3: Hippocampal volume } \\
\hline Intercept & 8.1893 & 1.0372 & $<0.0001$ \\
\hline TIV & 0.0023 & 0.0003 & $<0.0001$ \\
\hline Time from baseline, $y$ & -0.0751 & 0.0057 & $<0.0001$ \\
\hline Baseline age, $y$ & -0.0617 & 0.0124 & $<0.0001$ \\
\hline \multicolumn{4}{|l|}{ B. Low education models ( $<14$ y) } \\
\hline \multicolumn{4}{|l|}{ Model 1: Amyloid deposition ${ }^{a}$} \\
\hline Intercept & 0.1956 & 0.1868 & 0.2962 \\
\hline Time from baseline, $y$ & -0.0198 & 0.0015 & $<0.0001$ \\
\hline Baseline age, y & -0.0072 & 0.0024 & 0.0025 \\
\hline APOE4 & -0.1164 & 0.0288 & 0.0001 \\
\hline \multicolumn{4}{|l|}{ Model 2: FDG uptake } \\
\hline Intercept & 1.8534 & 0.1546 & $<0.0001$ \\
\hline Time from baseline, $y$ & -0.0093 & 0.0022 & $<0.0001$ \\
\hline Baseline age, y & -0.0058 & 0.0020 & 0.0035 \\
\hline APOE4 & -0.0625 & 0.0237 & 0.0091 \\
\hline \multicolumn{4}{|l|}{ Model 3: Hippocampal volume } \\
\hline Intercept & 9.3100 & 0.9766 & $<0.0001$ \\
\hline TIV & 0.0016 & 0.0003 & $<0.0001$ \\
\hline Time from baseline, $y$ & -0.0963 & 0.0066 & $<0.0001$ \\
\hline Baseline age, y & -0.0636 & 0.0110 & $<0.0001$ \\
\hline
\end{tabular}

Abbreviations: FDG = 18fluorodeoxyglucose; TIV = total intracranial volume. a Uses - In(Pittsburgh compound B) as the outcome.

For all the models predicting FDG uptake, older age and APOE4 status were associated with lower glucose metabolism, which has been found in previous studies. ${ }^{32-34} \mathrm{An}$ interesting finding was that $A P O E 4$ status was not associated with lower FDG uptake in the high-education subset, which implies that high education in APOE4 carriers may be protective via nonimpaired glucose metabolism. This may have been further observed by the differences in the amyloid deposition levels between participants with low cognitive activity vs high cognitive activity.

For the models predicting hippocampal volume, we found that older age was associated with lower hippocampal volume. Only the entire cohort model showed an association between older age and faster rate of hippocampal atrophy, which can be attributed to the larger sample required for detecting small effects (observed coefficient was -0.0025 ). APOE4 status did not influence the hippocampal atrophy trajectories. While decline of hippocampal volume with age has been well-established in the literature, ${ }^{35,36}$ the influence of APOE4 on hippocampal volume and rates of hippocampal atrophy has often been debated. ${ }^{37,38}$

In this longitudinal biomarker study, we did not find any direct effect of lifestyle enrichment variables on the rate of change of neurodegenerative biomarkers even though we had adequate power to detect associations of interest based on the sensitivity analyses. The effect of lifestyle enrichment on neurodegeneration is not unanimously agreed upon. ${ }^{3,4,8}$ The neurodegeneration biomarkers not only capture the disease-related effects (i.e., worsening of neurodegeneration with disease severity) but also capture structural and functional brain differences, e.g., genetic differences and compensatory mechanisms. Therefore, the effect of lifestyle enrichment on progression of neurodegeneration can yield different results depending on the biomarker and disease stage of the participants sampled.

There is substantial evidence that lifestyle enrichment is helpful in delaying the onset of cognitive impairment, but the mechanisms through which it delays impairment remain controversial. There may be 2 fundamental reasons for the controversial findings. First, the effect of lifestyle enrichment on AD biomarkers is small and only seen in select situations. Sample characteristics and sensitivity of the (lifestyle enrichment and biomarker) measures can yield significantly different findings. For example, in this study we did not see any effect of lifestyle enrichment in the overall sample, which is a population-based sample. Also, we only detected effects in highly educated individuals with $A P O E 4$ who had both higher levels of amyloid (APOE4 genotype) and higher neuroplasticity potential (high education). Second, there will be an impact of survivor and recruitment bias on the statistical models. For any biomedical study, persons with low educational attainment and low interest in novel activities tend to have a lower voluntary participate rate. Additionally, it is difficult to recruit older $A P O E 4$ carriers who do not have dementia due to the earlier onset of dementia in APOE4 carriers.

Unlike our prior work, we excluded data from current activities here because the existing 

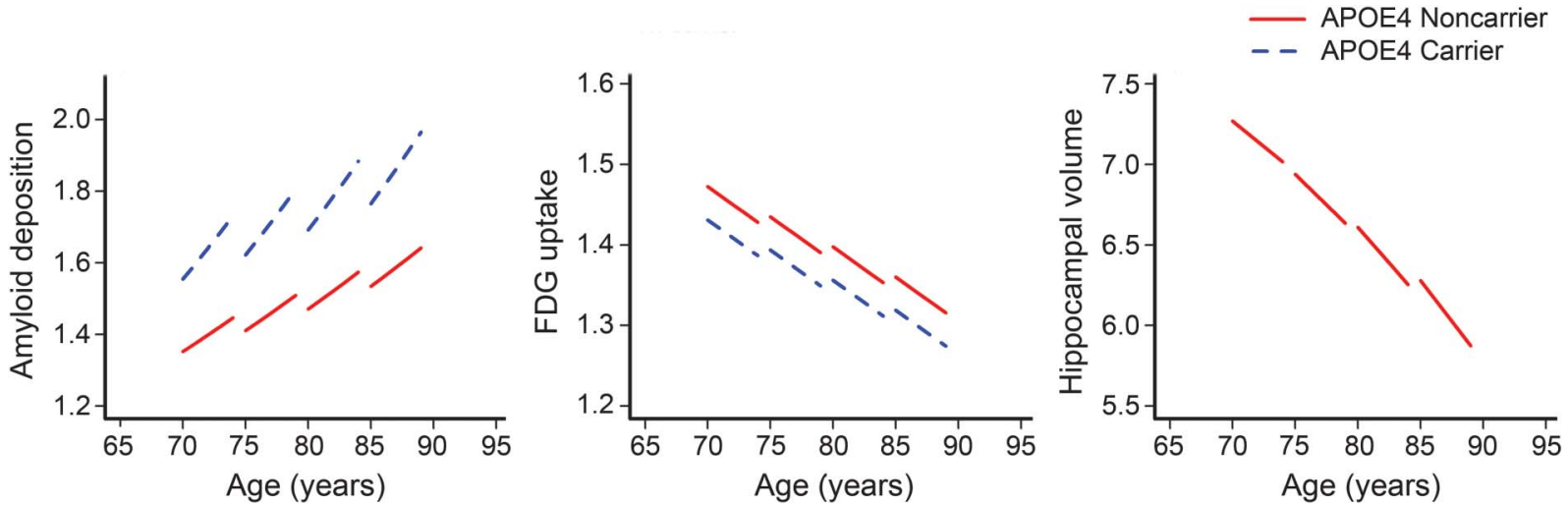

Longitudinal trajectories for predicted (left panel) amyloid deposition, (middle panel) ${ }^{18}$ fluorodeoxyglucose (FDG) uptake, and (right panel) hippocampal volume as a function of age. In each of the plots, the variables that significantly influenced the trajectories were also considered, i.e., APOE4 carrier status influenced amyloid deposition and FDG uptake.

neuropathologic processes may have an impact on the current physical and cognitive activities (i.e., reverse causality). We only included activity questionnaires that reported midlife physical and cognitive activities. The mean frequencies of the activities done by participants stratified by median education level (of 14 years) and median midlife cognitive activity level (of 19.5) are shown in table e-1 and figure e-2. Participants with high cognitive activity scores performed well across the board compared to those with low cognitive activity scores. The top 4 frequent activities in the high cognitive

Figure 2 Plots for biomarker outcome models run after education stratification
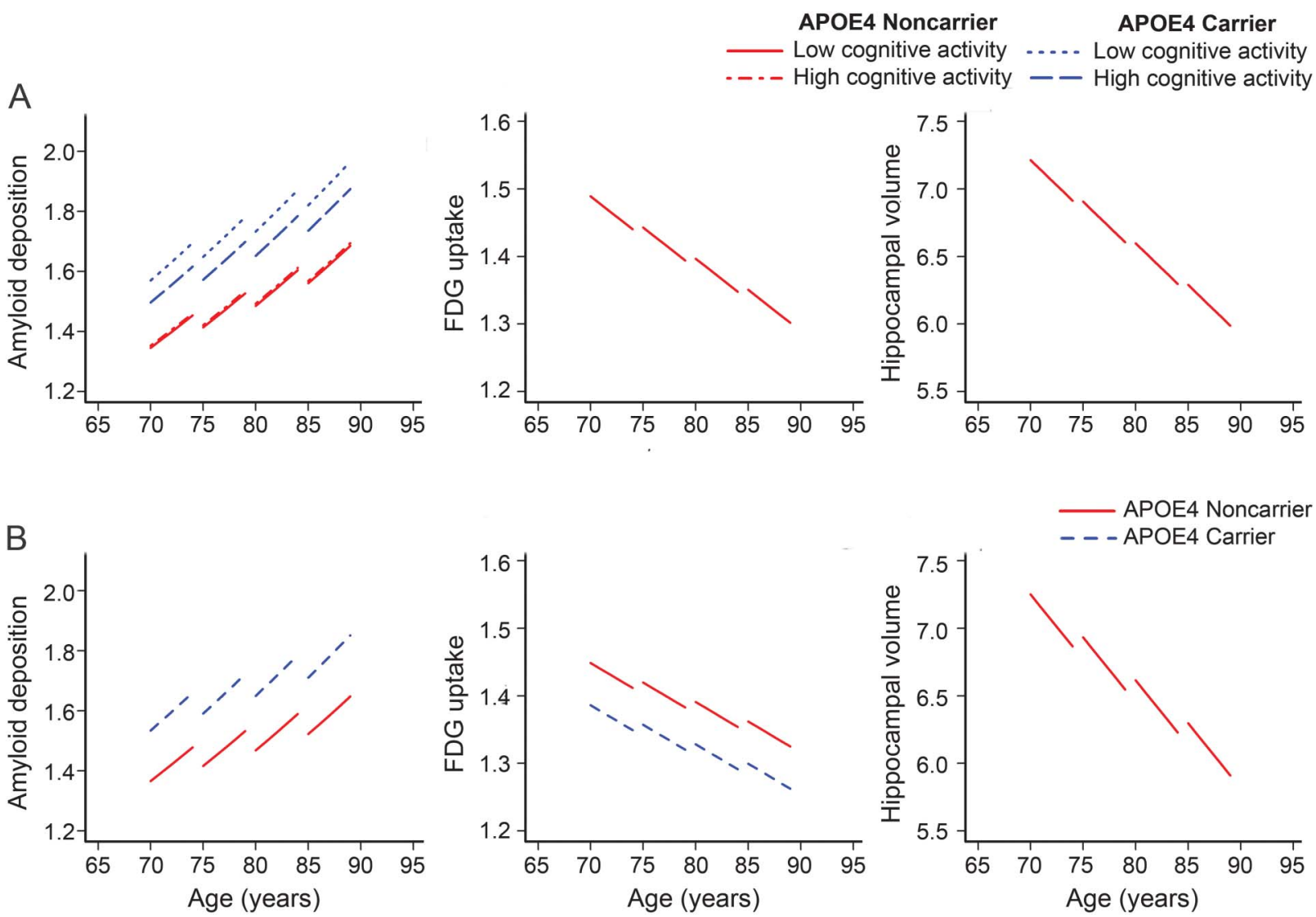

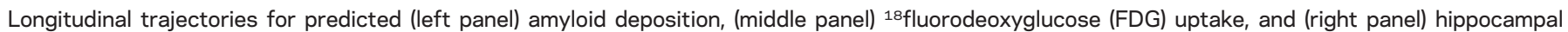

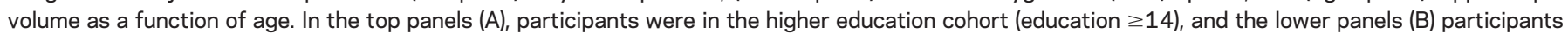

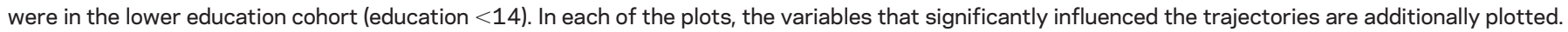
High cognitive activity was defined as the 67 th percentile, and low cognitive activity as the 33 rd percentile. 
activity group were reading books and magazines, computer activities, and playing games. A third of the population sampled fell in the category of low education and low cognitive activity and would benefit from engaging in midlife cognitive activities. ${ }^{39}$ Though we did not find associations with midlife physical activities, ongoing and planned active interventional trials may be better designed to observe these associations with physical activity. ${ }^{40}$

The limitations of this study are as follows. (1) We took a simplistic approach of investigating the influence of lifestyle enrichment on the $3 \mathrm{AD}$ biomarkers independently and did not consider the possible interactions between the different biomarker variables, which may be influenced by enrichment variables. (2) The AD biomarkers used in this study may not be capturing the brain compensatory mechanisms invoked by pathology due to lifestyle enrichment, e.g., recruitment of additional neuronal changes not measured here. (3) The activity questionnaires are self-reported.

\section{AUTHOR CONTRIBUTIONS}

Dr. Vemuri: study concept and design, study supervision, obtaining funding, interpretation of data, drafting and revising the manuscript for intellectual content. T.G. Lesnick: study design, analysis and interpretation of data. S.A. Pryzbelski: analysis and interpretation of data. Dr. Knopman: data collection, interpretation of data, revising the manuscript for intellectual content. Dr. Machulda: data collection, revising the manuscript for intellectual content. Dr. Lowe: data collection, revising the manuscript for intellectual content. Dr. Mielke: data collection, revising the manuscript for intellectual content. Dr. Roberts: data collection, revising the manuscript for intellectual content. Dr. Gunter: analysis of data, revising the manuscript for intellectual content. M.L. Senjem: analysis of data, revising the manuscript for intellectual content. Dr. Geda: data collection, revising the manuscript for intellectual content. Dr. Rocca: data collection, revising the manuscript for intellectual content. Dr. Petersen: obtained funding, data collection, revising the manuscript for intellectual content. Dr. Jack: obtaining funding, interpretation of data, data collection, revising the manuscript for intellectual content.

\section{STUDY FUNDING}

Supported by NIH grants R00 AG37573, P50 AG16574/P1, R01 AG11378, R01-AG041851, R01 AG034676, and U01 AG06786; and Opus building NIH grant C06 RR018898. The funding sources were not involved in the manuscript review or approval.

\section{DISCLOSURE}

P. Vemuri receives research funding from NIH/NIA. T. Lesnick and S. Przybelski report no disclosures relevant to the manuscript. D. Knopman serves as Deputy Editor for Neurology ${ }^{\circledR}$; serves on a Data Safety Monitoring Board for Lundbeck Pharmaceuticals and for the DIAN study; is an investigator in clinical trials sponsored by TauRX Pharmaceuticals, Lilly Pharmaceuticals, and the Alzheimer's Disease Cooperative Study; and receives research support from the NIH. M. Machulda receives research funding from the NIH. V. Lowe is a consultant for Bayer Schering Pharma and Piramal Imaging and receives research support from GE Healthcare, Siemens Molecular Imaging, AVID Radiopharmaceuticals, the NIH (NIA, $\mathrm{NCI}$ ), the Elsie and Marvin Dekelboum Family Foundation, the MN Partnership for Biotechnology and Medical Genomics, and the Leukemia \& Lymphoma Society. M. Mielke has served as a consultant for AbbVie and receives funding from NIH/NIA. R. Roberts receives research funding from the NIH. J. Gunter, M. Senjem, and Y. Geda report no disclosures relevant to the manuscript. W. Rocca receives research funding from the NIH. R. Petersen reports receiving consulting fees from Elan Pharmaceuticals and GE Healthcare, receiving royalties from Oxford University Press, and serving as chair of data monitoring committees for Pfizer and Janssen Alzheimer Immunotherapy; and receives research support from the NIH/ NIA. C. Jack serves as a consultant for Eli Lily and receives research funding from the NIH (R01-AG011378, RO1-AG041851, RO1-AG037551, U01-HL096917, U01-AG032438, U01-AG024904) and the Alexander Family Alzheimer's Disease Research Professorship of the Mayo Foundation. Go to Neurology.org for full disclosures.

Received June 23, 2015. Accepted in final form November 25, 2015.

\section{REFERENCES}

1. Wilson RS, Mendes De Leon CF, Barnes LL, et al. Participation in cognitively stimulating activities and risk of incident Alzheimer disease. JAMA 2002;287:742-748.

2. Verghese J, Lipton RB, Katz MJ, et al. Leisure activities and the risk of dementia in the elderly. $\mathrm{N}$ Engl J Med 2003;348:2508-2516.

3. Soldan A, Pettigrew C, Li S, et al. Relationship of cognitive reserve and cerebrospinal fluid biomarkers to the emergence of clinical symptoms in preclinical Alzheimer's disease. Neurobiol Aging 2013;34:2827-2834.

4. Almeida RP, Schultz SA, Austin BP, et al. Effect of cognitive reserve on age-related changes in cerebrospinal fluid biomarkers of Alzheimer disease. JAMA Neurol 2015;72:699-706.

5. Wilson RS, Boyle PA, Yu L, Barnes LL, Schneider JA, Bennett DA. Life-span cognitive activity, neuropathologic burden, and cognitive aging. Neurology 2013;81: 314-321.

6. Landau SM, Marks SM, Mormino EC, et al. Association of lifetime cognitive engagement and low beta-amyloid deposition. Arch Neurol 2012;69:623-629.

7. Matthews DC, Davies M, Murray J, et al. Physical activity, Mediterranean diet and biomarkers-assessed risk of Alzheimer's: a multi-modality brain imaging study. Adv J Mol Imaging 2014;4:43-57.

8. Wirth M, Haase CM, Villeneuve S, Vogel J, Jagust WJ. Neuroprotective pathways: lifestyle activity, brain pathology, and cognition in cognitively normal older adults. Neurobiol Aging 2014;35:1873-1882.

9. Head D, Bugg JM, Goate AM, et al. Exercise engagement as a moderator of the effects of APOE genotype on amyloid deposition. Arch Neurol 2012;69:636-643.

10. Wirth M, Villeneuve S, La Joie R, Marks SM, Jagust WJ. Gene-environment interactions: lifetime cognitive activity, APOE genotype, and beta-amyloid burden. J Neurosci 2014;34:8612-8617.

11. Rocca WA, Yawn BP, St Sauver JL, Grossardt BR, Melton LJ. History of the Rochester epidemiology project: half a century of medical records linkage in a US population. Mayo Clin Proc 2012;87:1202-1213.

12. Petersen RC, Roberts RO, Knopman DS, et al. Prevalence of mild cognitive impairment is higher in men: the Mayo Clinic Study of Aging. Neurology 2010;75:889-897.

13. Roberts RO, Geda YE, Knopman DS, et al. The incidence of MCI differs by subtype and is higher in men: the Mayo Clinic Study of Aging. Neurology 2012;78:342-351.

14. Jack CR Jr, Bernstein MA, Fox NC, et al. The Alzheimer's Disease Neuroimaging Initiative (ADNI): MRI methods. J Magn Reson Imaging 2008;27:685-691.

15. Reuter M, Schmansky NJ, Rosas HD, Fischl B. Withinsubject template estimation for unbiased longitudinal image analysis. Neuroimage 2012;61:1402-1418.

16. Jack CR Jr, Wiste HJ, Weigand SD, et al. Age, sex, and APOE epsilon4 effects on memory, brain structure, and 
beta-amyloid across the adult life span. JAMA Neuro 2015;72:511-519.

17. Lowe VJ, Kemp BJ, Jack CR Jr, et al. Comparison of 18FFDG and PiB PET in cognitive impairment. J Nucl Med 2009;50:878-886.

18. Senjem ML, Gunter JL, Shiung MM, Petersen RC, Jack CR Jr. Comparison of different methodological implementations of voxel-based morphometry in neurodegenerative disease. Neuroimage 2005;26:600-608.

19. Tzourio-Mazoyer N, Landeau B, Papathanassiou D, et al. Automated anatomical labeling of activations in SPM using a macroscopic anatomical parcellation of the MNI MRI single-subject brain. Neuroimage 2002;15:273-289.

20. Landau SM, Harvey D, Madison CM, et al. Comparing predictors of conversion and decline in mild cognitive impairment. Neurology 2010;75:230-238.

21. Vemuri P, Lesnick TG, Przybelski SA, et al. Effect of lifestyle activities on Alzheimer disease biomarkers and cognition. Ann Neurol 2012;72:730-738.

22. Ainsworth BE, Haskell WL, Herrmann SD, et al. 2011 compendium of physical activities: a second update of codes and MET values. Med Sci Sports Exerc 2011;43; $1575-1581$.

23. Ainsworth BE, Haskell WL, Herrmann SD, et al. The compendium of physical activities tracking guide [online]. Available at: https://sites.google.com/site/ compendiumofphysicalactivities/. Accessed February 20, 2015 .

24. Schelldorfer J, Buhlmann P, Van De Geer S. Estimation for high-dimensional linear mixed-effects models using e1-penalization. Scand J Stat 2011;38:197-214.

25. Villemagne VL, Burnham S, Bourgeat P, et al. Amyloid beta deposition, neurodegeneration, and cognitive decline in sporadic Alzheimer's disease: a prospective cohort study. Lancet Neurol 2013;12:357-367.

26. Sojkova J, Zhou Y, An Y, et al. Longitudinal patterns of beta-amyloid deposition in nondemented older adults. Arch Neurol 2011;68:644-649.

27. Brown B, Peiffer J, Taddei K, et al. Physical activity and amyloid- $\beta$ plasma and brain levels: results from the Australian Imaging, Biomarkers and Lifestyle Study of Ageing. Mol Psychiatry 2013;18:875-881.

28. Kivipelto M, Rovio S, Ngandu T, et al. Apolipoprotein E €4 magnifies lifestyle risks for dementia: a populationbased study. J Cell Mol Med 2008;12:2762-2771.
29. Rodrigue KM, Rieck JR, Kennedy KM, Devous MD, Diaz-Arrastia R, Park DC. Risk factors for $\beta$-amyloid deposition in healthy aging: vascular and genetic effects. JAMA Neurol 2013;70:600-606.

30. Head D, Bugg JM, Goate AM, et al. Exercise engagement as a moderator of the effects of APOE genotype on amyloid deposition. Arch Neurol 2012;69:636-643.

31. Jansen WJ, Ossenkoppele R, Knol DL, et al. Prevalence of cerebral amyloid pathology in persons without dementia: a meta-analysis. JAMA 2015;313:1924-1938.

32. Protas HD, Chen K, Langbaum JB, et al. Posterior cingulate glucose metabolism, hippocampal glucose metabolism, and hippocampal volume in cognitively normal, late-middleaged persons at 3 levels of genetic risk for Alzheimer disease. JAMA Neurol 2013;70:320-325.

33. Kantarci K, Senjem ML, Lowe VJ, et al. Effects of age on the glucose metabolic changes in mild cognitive impairment. AJNR Am J Neuroradiol 2010;31:1247-1253.

34. Reiman EM, Caselli RJ, Chen K, Alexander GE, Bandy D, Frost J. Declining brain activity in cognitively normal apolipoprotein E epsilon 4 heterozygotes: a foundation for using positron emission tomography to efficiently test treatments to prevent Alzheimer's disease. Proc Natl Acad Sci USA 2001;98:3334-3339.

35. Jack CR Jr, Petersen RC, Xu Y, et al. Rates of hippocampal atrophy correlate with change in clinical status in aging and AD. Neurology 2000;55:484-489.

36. Carlson NE, Moore MM, Dame A, et al. Trajectories of brain loss in aging and the development of cognitive impairment. Neurology 2008;70:828-833.

37. Jak AJ, Houston WS, Nagel BJ, Corey-Bloom J, Bondi MW. Differential cross-sectional and longitudinal impact of APOE genotype on hippocampal volumes in nondemented older adults. Dement Geriatr Cogn Disord 2007;23:382-389.

38. Jack CR Jr, Petersen RC, Xu YC, et al. Hippocampal atrophy and apolipoprotein $\mathrm{E}$ genotype are independently associated with Alzheimer's disease. Ann Neurol 1998;43:303-310.

39. Vemuri P, Lesnick TG, Przybelski SA, et al. Association of lifetime intellectual enrichment with cognitive decline in the older population. JAMA Neurol 2014;71:1017-1024.

40. Phillips C, Baktir MA, Srivatsan M, Salehi A. Neuroprotective effects of physical activity on the brain: a closer look at trophic factor signaling. Front Cell Neurosci 2014; $8: 170$.

\section{Save These Dates for AAN CME Opportunities!}

Mark these dates on your calendar for exciting continuing education conferences by the American Academy of Neurology. Learn more at AAN.com/conferences.

\section{AAN Annual Meeting}

- April 15-21, 2016, Vancouver, BC, Canada, Vancouver Convention Centre 


\section{Neurology}

\section{Effect of intellectual enrichment on AD biomarker trajectories: Longitudinal imaging study \\ Prashanthi Vemuri, Timothy G. Lesnick, Scott A. Przybelski, et al.}

Neurology 2016;86;1128-1135 Published Online before print February 24, 2016

DOI 10.1212/WNL.0000000000002490

This information is current as of February 24, 2016

\section{Updated Information \& Services}

Supplementary Material

\section{References}

Citations

Subspecialty Collections

\section{Permissions \& Licensing}

Reprints including high resolution figures, can be found at: http://n.neurology.org/content/86/12/1128.full

Supplementary material can be found at: http://n.neurology.org/content/suppl/2016/02/24/WNL.0000000000002 490.DC1

This article cites 39 articles, 10 of which you can access for free at: http://n.neurology.org/content/86/12/1128.full\#ref-list-1

This article has been cited by 4 HighWire-hosted articles: http://n.neurology.org/content/86/12/1128.full\#\#otherarticles

This article, along with others on similar topics, appears in the following collection(s):

\section{Alzheimer's disease}

http://n.neurology.org/cgi/collection/alzheimers_disease

Cognitive aging

http://n.neurology.org/cgi/collection/cognitive_aging

Information about reproducing this article in parts (figures,tables) or in its entirety can be found online at:

http://www.neurology.org/about/about_the_journal\#permissions

Information about ordering reprints can be found online: http://n.neurology.org/subscribers/advertise

Neurology ${ }^{\circledR}$ is the official journal of the American Academy of Neurology. Published continuously since 1951, it is now a weekly with 48 issues per year. Copyright @ 2016 American Academy of Neurology. All rights reserved. Print ISSN: 0028-3878. Online ISSN: 1526-632X.

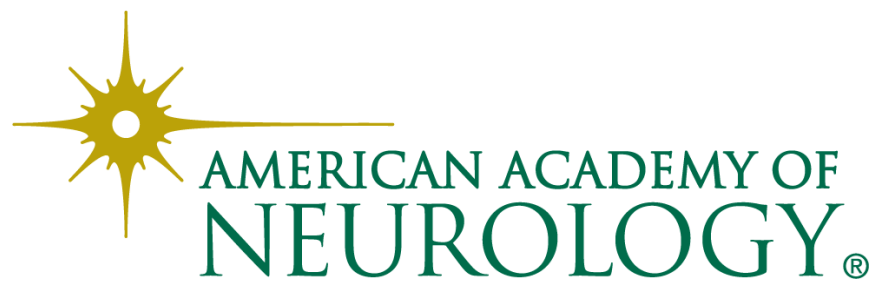

